\section{Fungal Infection of Central Nervous System Supervening During Routine Chemotherapy for Pulmonary Tuberculosis}

Brit. med. F., 1965, 2, 862

This report describes a case in which there is the possibility that long-term antibiotics and steroids for acute tuberculosis may have predisposed the patient to a central-nervous-system infection from a respiratory fungus.

\section{History AND Course of ILLNESS}

An Irish labourer aged 50, probably a mild alcoholic, was admitted to the Royal National Hospital, Bournemouth, in December 1963 critically ill with gross pulmonary tuberculosis. Tubercle bacilli were abundant in the sputum, and fully sensitive to streptomycin, para-aminosalicylic acid, and isoniazid. Chest $x$-ray examination showed shadowing in all zones of both lungs with bilateral cavitation. His haemoglobin was $50 \%$, and several occult blood tests were positive. Treatment was begun with streptomycin 1 g. daily, P.A.S. 15 g. daily, and isoniazid $300 \mathrm{mg}$. daily. Because of his severely toxic condition he was also given prednisone $20 \mathrm{mg}$. daily. He responded well to treatment. At the end of January his prednisone was reduced to $15 \mathrm{mg}$. daily, and toward the end of February to $10 \mathrm{mg}$. daily. By this time he was getting up to toilet freely and had gained a stone and a half $(9.5 \mathrm{~kg}$.) in weight; his haemoglobin was $75 \%$, serial $x$-ray films showed progressive resolution, and his daily sputum had declined from $1 \mathrm{oz}$. $(28 \mathrm{ml}$.) of pus to a trace of mucoid material. His sputum was negative on direct smear after one month, and two cultures in early February gave no growth of tubercle bacilli.

On 26 February 1964 he complained of upper abdominal pain and stiffness in the left leg. Three days later, still complaining of pain, his temperature was $99^{\circ} \mathrm{F}$. $\left(37.2^{\circ} \mathrm{C}\right.$.) and his pulse 130 ; an occult blood test was positive; a routine clinical examination of the central nervous system disclosed no abnormal signs. The next day his temperature was $101^{\circ} \mathrm{F}$. $\left(38.3^{\circ} \mathrm{C}\right.$.) and pulse 120 , and he complained of diarrhoea. On 5 March all three anti-tuberculous drugs were suspended to exclude any sort of drug reaction from the differential diagnosis of these new symptoms. The next day he was more poorly and drowsy ; in the morning of 7 March he developed retention of urine and incontinence of faeces. That afternoon he was delirious, with neck rigidity, unequal pupils, and extensor plantar response. Lumbar puncture disclosed cerebrospinal fluid under normal pressure, cloudy in appearance, with low chloride (580 mg./100 ml.) and sugar content (32 mg./100 ml.), and a cell count of $2,800 /$ c.mm. ( $98 \%$ polymorphonuclear). Subsequent routine and Löwenstein culture of the cerebrospinal fluid showed no growth. Eight hours later he died.

Post-mortem Findings.-The leptomeninges of the cerebrum were slightly thickened and soft adhesions were present over the cerebellum. The brain substance was of normal consistency, and no gross abnormality was detected in the brain parenchyma. The choroid plexus was hyperaemic and pale-green pus surrounded the hypophyseal stalk. Similar pus exuded from the right ninth rib anteriorly when the chest was opened. The fibrotic lungs were adherent to the chest wall and there were some thin-walled caseous cavities in the left upper lobe. Microscopically there were exudative lesions in the choroid plexus, with branching septate hyphae intimately mixed with polymorphs, and some necrosis was present. Hyphae with surrounding acute inflammatory cells were also seen in the brain parenchyma close to the ventricular surface. The chestwall pus revealed no acid-fast organisms on direct smear. Unfortunately, no verification of the precise nature of the fungus was obtained by culture. However, it fulfils the morphological criteria of the Aspergillus group as described by Zimmerman (1950), consisting of regular, rather broad septate hyphae with frequent branching, but with no spore-formation in the tissue.

\section{COMMENT}

Burston and Blackwood (1963) were able to find only 14 previous cases of aspergillus infection of the central nervous system in the literature prior to the one they described. Nevertheless there has been considerable increase in fungal infection generally in recent years. Keye and Magee (1956), reviewing 15,845 consecutive necropsies, believed that this trend was related to the increased use of multiple antibiotics, chemotherapeutic compounds, and cortisone, and several observers have reported series of fungal infection associated with such therapy (Craig and Farber, 1953 ; Zimmerman, 1955 ; Torack, 1957).

The clinical conditions necessary for a significant and perhaps fatal fungal infection appear to be: (a) a source of fungus -aspergillus infection, unlike that of candida, is usually exogenous; (b) a locally destructive lesion-for example, pulmonary cavitation or peptic ulcer-where a focus of infection may be established; this may be facilitated by disturbance of the normal flora by previous antibiotics ; and (c) dissemination of the fungus, which may be encouraged by the debility of the patient or depression of antibody response by primary disease-for example, tuberculosis, leukaemia, malignant lymphoma-or by steroids or A.C.T.H.

In 13 necropsy cases of fungal infection of various types Torack found a direct correlation between the presence of tissue invasion by the fungus and the administration of cortisone. In most of those who had not received cortisone the fungus was limited to the surface of the mucous membranes.

In the case recorded here it would appear that the treatment of cavitating tuberculosis with long-term chemotherapy and steroids led to secondary invasion of the respiratory tract, and thence the chest wall, by a fungus, probably aspergillus, which subsequently gained access to the central nervous system. The possibility of a fungal infection of the central nervous system should be borne in mind whenever a patient under active treatment for tuberculosis dies unexpectedly or with symptoms of meningitis.

$$
\begin{aligned}
& \text { NORA SPENS, M.B., B.S., } \\
& \text { Pathologist. } \\
& \text { W. H. TATTERSALL, M.A., M.D., } \\
& \text { Consultant Chest Physician. }
\end{aligned}
$$

Bournemouth.

Burston, J and Blackwood, W. (1963). 7. Path. Bact., 86, 225.

Craig, J. M., and Farber, S. (1953). Amer. F. Path., 29, 601 .

Keye, J. D., and Magee, W. E. (1956). Amer. 7. clin. Path., 26, 1235.

Torack, R., M. (1957). Amer. F. Med., 22, 872.

Zimmerman, L. E. (1950). Arch. Path., 50, 591.

(1955). Amer. f. clin. Path., 25, 46. 